\title{
Factors Affecting Dairy Producers' Participation in Dairy Processing and the Level of Participation in Bishoftu Town, East Shewa, Oromia, Ethiopia
}

\author{
Gudeta Shanko Fikadu Mitiku (PhD) Tura Kaso \\ Department of Agribusiness and Value Chain Management, Ambo University, Ambo, Ethiopia
}

\begin{abstract}
There are potentials for dairy production and processing in Ethiopia. However, producers are dominated by small scale dairy producers who sold fresh than processing to its products in Bishoftu town. Dairy producer's participation in dairy processing was analyzed by objectives of factors affecting producers' participation in dairy processing and level of processing. Data were collected through Censuses of 141 dairy producers and it was conducted by dividing them into three different scale farm producers. Accordingly producers who have 1-5 dairy cows were categorized as small scale producers, 6-10 medium scale producers and $>11$ dairy cows were taken as large scale dairy farms. Based on this classification there were 100, 34, and 7 small, medium and large scale dairy respectively in the town. Among these producers 25 small scale, all 34 medium scale and 6 large scale dairy producers were processors. It was assumed that all large scale were processors, but one producer was found to be non-processor and was omitted from census survey. So, the survey was conducted with 140 dairy producers in the town. Data were analyzed using econometric models, Heckman two stages. The result of the first stage probit model indicated that number of adults negatively affects producers' participation in dairy processing; whereas total dairy output per cow and training affect positively and significantly. In Heckman second stage model, the number of adults in the household negatively affects the level of processing while total dairy output per cow, land holding, access to dairy processing equipment and dairy related training in dairy processing affect positively and significantly. Therefore, producers' socioeconomic factors and institutional factors needed to be strengthened by supportive activities like training for capacity building of producers.
\end{abstract}

Keywords: Dairy, processing, Censuses, Bishoftu, probit

DOI: $10.7176 / \mathrm{JRDM} / 61-02$

Publication date: November $30^{\text {th }} 2019$

\section{INTRODUCTION}

\section{Background of study}

Ethiopia holds the largest livestock population in Africa, estimated at about 57.8 million of which female livestock constitute about 56.38 percent. It is estimated that there are 6.74 million dairy cows and 11.34 million milking cows (Ruerd et al., 2017). The total volume of milk produced in Ethiopia increased over the last 15 years from less than 1 billion liters to 3.06 billion liters (CSA, 2016/17). The dairy sector contribution to the national Gross Domestic Product is expected to increase in the years to come too. The overall country milk production expected to surpass existing milk demand (2016-2020) projection with about 2501 million liters that is above 47\% (ILRI, 2015). As per the plan the surplus of milk could then be substituted for imported milk products and used domestically for new or additional industrial uses. Milk production is an important part of the Ethiopian livestock production systems. Cattle, camels, goats and sheep are the main livestock species that supply milk in the country, with cow's milk constituting $83.4 \%$ of the total annual milk output of the country.

Dairy producers' in the town are categorized into small, medium and large scales dairy producers. They all are market oriented and commercialized so that they produce for market. They all also raised improved breed cows (Bishoftu town administration dairy department, 2017). This study tried to analyze producer's participation and level of participation of dairy producers in the town by identifying factors affecting producers' participations in further dairy value addition (dairy processing) and level processing of dairy products.

\section{LITERATURE}

\section{Livestock Production in Ethiopia}

According to (CSA, 2016/2017) Ethiopia is home to the largest livestock populations in Africa with approximately 50 million cattle, 50 million sheep and goats, plus an assortment of horses, donkeys camels and chickens. The country is repetitively exemplified as the most potential country in livestock resources.

Cattle in Ethiopia are almost entirely of the zebu type and are sources of milk and meat. However, these cattle do relatively well under the traditional production system. About 70 percent of the cattle are in the highlands, and the remaining 30 percent are kept by pastoralists in the lowland areas. Meat and milk yields are low and losses high, particularly among calves and this stock. Contagious diseases and parasitic infections are major causes of death, factors that are exacerbated by malnutrition and starvation due to frequent drought. 
Recurring drought is a factor for the loss of huge livestock resource that influences the animal population, although it is difficult to determine the extent of losses. Practically all animals are range-fed. During the rainy seasons, water and grass are generally plentiful, but with the onset of the dry season, forage is generally insufficient to keep animals nourished and able to resist disease (Yonad, 2009).

Livestock production is either the major form of engagement in the highland and mid altitude crop livestock production systems It provides multiple functions as a source of meat, milk and egg production, sources of draft power and manure to support crop production, means of transport particularly in rural areas, sources of foreign currency through export of chilled meat, live animals, skin, hides and others. The productivity is far below the possible expectations and the country could not fulfill the national demand. Hence, importing milk powder and other products, having huge livestock population, in this situation is a paradox (EARO, 2001)

\section{Factors Affecting Producers' Participation in Dairy Processing and Level of Participation}

Charles and Rebecca (2016) figured out determinants of smallholder farmeres participation in Zambian dairy sector using double-hurdle model and identified milk price and access to dairy marketing information were positively affected smallholder farmers participation in dairy sector while income from other sources and landholding size affected participations of smallholder farmers in dairy sector negatively

Noreen et al (2014) identified factors influencing urban and per-urban dairy producers ${ }^{\text {ee }}$ participation in milk value addition in Welmera woreda using Heckman second stages econometric model. The first stage Heckman test showed sex, age, education, market distance and number of local milking cow affected participation positively. In the second stage sex, income from non- dairy source, market distance and number of local milking cow affected volume of milk produced positively, whereas number of children under six age, number of cross breed cow affected it negatively.

Gizachew (2005) analyzed factors affecting dairy producer household dairy market entry decision which have contribution to dairy value addition (using Logit model) and marketed milk surplus (using Tobit model) in Adea Liben district in Oromia region. His findings revealed that education level of household head, extension visits and income from nondairy sources had positive effects on entry decision. He also found that dairy cow breed, loan, income and extension visit, education level and distance nearest to market positively affected marketed surplus. Nevertheless, he did not consider the contribution of household access to milk market information, credit sources and separated contributions of modern and traditional production techniques. Moreover, he considered dairy cow breed as dummy variable which is difficult to see the marginal contribution of local and crossbred cows.

Berhanu (2012) used Heckman two-stage model, to identify determinants of participation decision and level of participation in-farm level milk value addition in Wolaita zone, Ethiopia. The first-stage probit model estimation results for participation decision indicated that milk yield in liter per day, distance from urban centers, household demography (age and child), access to livestock extension services, the need to extend shelf life, consideration of milk products for social factors such as holidays and fasting, and availability of labor for milk value addition determined household's level of decision to add values to milk. He also identified the factors determining decision of participation in milk value addition. Age and access to extension services negatively and significantly affect participation milk value addition whereas children less than 6 years old and distance from market affect milk value addition participation positively and significantly, and he also determined the level of participation.

Betela (2016) used descriptive statistics (chi2 and t-test) to identify dairy value addition participation decision and level of dairy value chain in Essera district Ethiopia. The maximum and minimum dairy value additions were 3.75 liters and 0 liter respectively. He indicated that on average 2.03 liters dairy was produced per household per day and 1.04 liter was processed to butter and cottage cheese whereas the remaining was consumed at home as fluid milk. He also investigated breed of dairy cows, value addition experience, and nondairy source of income were brought about the difference between quantity of dairy and level of dairy value addition among dairy producers. There were again shortages of feed that limit volume of dairy in the area according to this study.

\section{RESEARCH METHODS}

Description of the Study Area: This study was undertaken in south Eastern Part of Ethiopia in potential district (namely of Oromia regional state) in dairy production. Description for the town is given below: Bishoftu is located at $45 \mathrm{~km}$ distance from Addis Ababa in South East (Figure 2). The area is located at $9^{\circ} \mathrm{N}$ latitude and $40^{\circ} \mathrm{E}$ longitude at altitude of $1850 \mathrm{~m}$ with annual rain fall of $866 \mathrm{~mm}$, of which $84 \%$ is in the long rainy season June to September. The annual average temperature ranges from $12.3 \mathrm{oC}$ to $27.7 \mathrm{oC}$ with an overall average of $18.7 \mathrm{oC}$. The soil and climate are similar to those in many highland areas in Ethiopia. It is an important town where most governmental institutions, national and international research centers are located. Cattle, small ruminant, poultry and equines are the major livestock species kept with fast growing small scale dairy production 
(NMSA, 2010).

Type and Sources of Data: This study depends on cross sectional study design in which both quantitative and qualitative type of data were used. The data were collected from primary and secondary sources.

Sampling Procedure and Sample Size: This study used census of dairy producers in the town to collect data from a total of 141 respondents. In Bishoftu town there are 100 small scale, 34 medium scale and 7 large scale dairy producers.

Methods of Data Collection: questionnaire were used to collect data from dairy producers, processors and other actors who participate in dairy value chain in the town. It is believed to generate policy relevant information that can provide guidance for development interventions and for guiding formal survey. Thus, interview with key informants and value chain actors at various levels within the town were conducted.

\section{Methods of Data Analysis Econometric Analysis}

In order to identify determinants of dairy producers' participations in further dairy value addition and their level of participation, Heckman two stage model was used to analyze the survey data. This type of analysis is popular because it is easy to use, should be treated only as a preliminary step, but not as a final analysis, as is often done. The results are sensitive to distributional assumptions and are also often uninformative about the basic economic decisions that produce the selectivity bias. One should think more about these basic decisions and attempt to formulate the selection criterion on its structural form before the Heckman correction is even applied (Maddala 1985, p. 16).

This was done by sequential two stage decision making process. In the first stage, producers' make a discrete decision whether they participate or not participate in farther dairy value addition (processing). In the second stage, conditional on their decision whether to process, dairy producers make continuous decision on the level of participation. In the first stage, the standard probit model was used, which can be illustrated as follows (Wooldridge 2002):

$$
\begin{aligned}
& \mathrm{Y} *=\mathrm{Z}^{\prime} \partial+£ 1 \\
& \mathrm{Y}=1 \text { if } \mathrm{Y} *>0 \\
& \mathrm{Y}=0 \text { if } \mathrm{Y} * \leq 0 \text { Where, }
\end{aligned}
$$

$\mathrm{Y}^{*}=$ is a latent (unobservable) variable representing dairy farm discrete decision whether to participate or not participate in dairy processing.

$Z^{\prime}$ = is a vector of independent variables (household heads' age, sex, education, access to credit, adult labor equivalent, type of dairy cows, dairy output per cow, non-farm participation, land holding, cooperative membership, access to dairy processing equipment, dairy related training and access to market information) hypothesized to affect dairy producers decision to participate in farther dairy value addition

$\partial=$ is a vector of parameters to be estimated which measures the effects of explanatory variables on the farms decision

$£_{1}=$ is normally distributed disturbance term with mean $(0)$ and standard deviation $(\sigma) 1$, and captures all unmeasured effects

$\mathrm{Y}=$ is a dependent variable which takes a value 1 if the producers participate in dairy processing and 0 if they sell raw milk.

Conditional on participation decision, the variables determining intensity of participation are modeled using the second-stage Heckman selection model (Heckman, 1979). The Heckman selection equation is specified as:

$\mathrm{Zi} *=\mathrm{Wi}^{\prime} \sigma+£ 2$

$$
\begin{aligned}
& \mathrm{Zi}=\mathrm{Zi} * \text { if } \mathrm{Zi} *>0 \\
& \mathrm{Zi}=0 \text { if } \mathrm{Zi} * \leq 0
\end{aligned}
$$

Where,

$\mathrm{Zi}^{*}=$ latent variable representing the desired or optimal level of participation which is observed if $\mathrm{Zi}^{*}>0$ and unobserved otherwise

$\mathrm{Zi}=$ is the observed level of participation

$\mathrm{Wi}=$ vector of covariates for unit i for selection equation which is a subset of $Z^{\prime}$

$\sigma=$ vector of coefficients for selection equation

$£ 2$ = random disturbance for unit $\mathrm{i}$ for selection equation

\section{RESULTS AND DISCUSSIONS}

Factors Affecting Producers' Participation in Dairy Processing and Level of Participation

The econometrics analysis of Heckman two steps estimation procedures was performed using STATA version 13 software. Heckman two steps procedure was employed in order to control the selectivity bias and endogenity 
problems and obtain consistent and unbiased parameter estimates. Accordingly this study used probit selection model for participation equation which was found to affect the producers' participation in dairy processing, but has no significant impact on level (capacity) of processing for dairy producers.

\section{The Binary Probit Results}

The model output reports result of estimation of variables that were expected to determine dairy processing participation of individual households. In binary probit equation, 3 variables were significantly determining the probability of participation of producers dairy processing. These were number of adult, total dairy/milk output per cow per day and dairy related training.

Table 1: First stage probit estimation results of determinants of probability participation in dairy/milk processing

\begin{tabular}{|c|c|c|c|c|}
\hline Variables & Coef & $\begin{array}{c}\text { Marginal } \\
\text { effect }\end{array}$ & Std. Err. & $\mathrm{P}>\mathrm{Z}$ \\
\hline cons & -3.42 & - & 2.47 & 0.17 \\
\hline$\overline{\text { Leduca }}$ & - & - & - & - \\
\hline primary sc (grade 1-8) & -0.89 & -8 & 0.82 & 0.28 \\
\hline secondary sc (grade 9-12) & -33.97 & -20 & 526.34 & 0.95 \\
\hline University without degree & 0.85 & 13 & 0.79 & 0.28 \\
\hline university with degree & 0.19 & 2 & 0.80 & 0.81 \\
\hline churches and mosques & 1.35 & 22 & 0.87 & 0.12 \\
\hline Basic education & -15.75 & -14 & - & - \\
\hline Credit & 0.00 & 0.00 & 0.00 & 0.14 \\
\hline Nadult & -0.40 & -5 & 0.19 & $0.038 * *$ \\
\hline Toupc & 0.16 & 2 & 0.10 & $0.09 *$ \\
\hline Sex & -0.56 & -6 & 0.46 & 0.23 \\
\hline Age & .01 & 0.00 & 0.03 & 0.77 \\
\hline Typec & - & - & - & - \\
\hline exotic breed & 0.02 & 0.00 & 0.44 & 0.97 \\
\hline Ndocop & -0.03 & 0.00 & 0.54 & 0.95 \\
\hline Landow & 0.00 & 0.00 & 0.00 & 0.69 \\
\hline Mcoop & 0.65 & 8 & 0.44 & 0.13 \\
\hline Dequip & 35.28 & 410 & 526.38 & 0.95 \\
\hline Trainig & 0.63 & 7 & 0.24 & $0.009 * * *$ \\
\hline
\end{tabular}

Source: Computed from survey result, 2018

Dependent variable $=$ determinants of probability of dairy/milk processing for dairy producers

Observations $(\mathrm{N})=140$, Log likelihood $=-29.080416$, Pseudo $\mathrm{R}^{2}=0.6992$, Prob $>$ chi2 $=0.0000$, and ***,**, and $*$ represents significance level at $1 \%, 5 \%$ and $10 \%$ probability level respectively.

\section{The Results of Heckman Second Stage Estimation}

The results of second-stage Heckman selection estimation for the level of participation in dairy processing are given in Table 9. The coefficient of Mills ratio (Lamda) in the Heckman two-stage estimation is significant at the probability of less than $5 \%$. This indicates sample selection bias, existence of some unobservable dairy producers characteristics determining producer's likelihood to add values to dairy/milk (processing) and thereby affecting the level of participation. Five variables were significant in dairy processing capacity (level of processing). These were number of adult, total milk output per cow, land holding, Access to dairy processing equipment, and dairy related training. 
Table 2: Results of second stage Heckman selection estimation of determinants of level (capacity) of producers' dairy processing.

\begin{tabular}{lccc}
\hline Variables & Coef. & Std. Err. & P $>\mathrm{Z}$ \\
\hline cons & -221.90 & 99.60 & 0.03 \\
Leduca & - & - & - \\
primary sc (grade 1-8) & 12.30 & 40.36 & 0.76 \\
secondary sc (grade 9-12) & 29.46 & 50.68 & 0.56 \\
University without degree & 46.81 & 44.04 & 0.29 \\
university with degree & 59.27 & 47.75 & 0.21 \\
churches and mosques & 56.66 & 45.48 & 0.21 \\
Basic education & -1.12 & 58.74 & 0.99 \\
Credit & 0.00 & 0.00 & 0.88 \\
Nadult & -9.60 & 4.43 & $0.03 * *$ \\
Toupc & 5.75 & 2.69 & $0.032^{* *}$ \\
Sex & 16.59 & 15.50 & 0.28 \\
Age & 1.57 & 1.08 & 0.15 \\
Typec & - & - & - \\
exotic breed & -0.15 & 14.75 & 0.99 \\
Ndocop & -27.24 & 20.88 & 0.19 \\
Landow & 0.01 & 0.00 & $.0 * * *$ \\
Mcoop & 8.23 & 0.61 \\
Dequip & 51.84 & 16.02 & $0.075^{*}$ \\
Trainig & 9.07 & 29.15 & $0.058^{*}$ \\
Lambda & 51.24 & 4.79 & $0.044^{* *}$ \\
\hline Source: Computed & 25.49 & \\
\hline
\end{tabular}

Source: Computed from survey result, 2018

Dependent variable $=$ producers dairy processing capacity, observation $(\mathrm{N})=140$, Censored observations 65 Uncensored observations $=75$, Wald chi2 $(17)=80.60(000)$, Rho $=1.00000$, sigma $=51.244015, * * *, * *$ and $*$ indicate statistical significance at $1 \%, 5 \%$ and $10 \%$ respectively.

\section{CONCLUSION AND RECOMMENDATION}

\section{Conclusion}

This study analyzed by identifying factors affecting participation of producers in dairy processing and level of processing. The data for this study were collected from 140 dairy producers. Econometric model, SPSS and STATA software were used. All producers were commercialized and market oriented.

The results of Heckman two stage models identified that number of adults, total dairy output per cow, land holding, access to dairy processing equipment's and dairy related training were determinants of producers' in dairy processing capacity (level of processing) whereas in dairy processing participation number of adults, total output per cow and training were significant. Number of adult was expected to affect both producers participation in dairy processing and capacity of participation positively. But, contrary to expectation the model output depicted as it negatively affected both participation and capacity of dairy producers in dairy processing. The other significant variables listed above affected participation of dairy processing in dairy processing and level of participation as they were expected

\section{Recommendation}

The results of econometric analysis revealed that, total dairy output per cow and training affected participation of producers in dairy processing positively and significantly. Therefore producers' socioeconomic factors, infrastructures and information factors needed to be considered and strengthened by supportive activities like, training provision and capacity building so that producers can participate in dairy processing and expand their production.

\section{Acknowledgement}

We wish to appreciate the efforts, support and encouragement from God, several individuals and organizations when undertaking this research work. We are grateful to God, my creator and author of my faith for the grace, peace and mercies that have dominated my study period and my entire life.

\section{REFERENCES}

Betela, B., 2016. Value chain analysis of dairy products in Esssera district Dawrozone, southern Ethiopia. Industrial Engineering Letters, ISSN 2224-6096 (Paper) ISSN 12225 - 0581 (online), Vol.6, No.6, 2016

Berhanu, K., 2012. Market access and value chain analysis of dairy industry: A wolaita zone for partial 
fulfillment of the requirement for the degree of philosophy of doctor in Agricultural economics

Bishoftu town administration dairy department, 2017. Physical and socioeconomic profile and dairy department of Bishoftu town, Ethiopia, physical interview of experts and administrative bodies.

Charles, M., Rebecca, K., (2016). Determinants of smallholder farmers' participation in Zambian dairy sector's Interlocked Contractual Arrangements. Journal of Sustainable Development; Vol. 9, No. 2; 2016 ISSN 1913-9063 E-ISSN 1913-9071 Published by Canadian Center of Science and Education.

CSA, 2016. Agricultural Sample Survey Livestock and Livestock Characteristics.

Ethiopian Agricultural Research Organization (EARO), 2001. Background Paper on Developing Animal Breeding Policy. A working paper, January 2001, Pp 21.

Gizachew, G., 2005. Dairy marketing patterns and efficiency: The Case of Ada ${ }^{e e}$ Liben District,eastern Oromia. M.Sc. Thesis, Alemaya University, Ethiopia.

ILRI, 2015. Livestock Master Plan.

Maddala, GS., (1985). survey of the literature on selectivity bias as it pertains to healthcare markets Adv Health Econ Health Serv Res 6:3-18

NMSA, 2010. National Metrological Agency of Addis Ababa, Ethiopia

Noreen, B., Tadele, M., Tewodros, T., (2014). Factors influencing urban and per- urban dairy producer's participation in milk value addition. International journal of livestock production, Vol. 5(9). Pp 165-172, September, 2014.

Ruerd, R., Alemayehu, D., and Birhanu, M., 2017: Quality upgrading in ethiopian dairy value chains: dovetailing upstream and downstream perspectives, Review of Social Economy, DOI: 10.1080/00346764.2017.1286032

Wooldridge, MJ., 2002.Econometric Analysis of Cross Section and Panel Data.The MIT Press, Cambridge, Massachusetts London, England.

Yonad, 2009. Value chain Analysis of Milk and Milk products in Borana pastoralist area, unpublished manuscript. 2009. 